\title{
Ciberviolencia en la red. Nuevas formas de retórica disciplinaria en contra del feminismo
}

\author{
Inés Crosas Remón \\ Pilar Medina-Bravo \\ Universitat Pompeu Fabra. Departamento de Comunicación \\ ines.crosas01@estudiant.upf.edu; pilar.medina@upf.edu
}

\section{Resumen}

La ciberviolencia ejercida en contra de la mujer está emergiendo como un problema global. Los crecientes casos de youtuberas feministas acosadas online demuestran que esta agresión aumenta cuando afecta a una mujer que además es feminista. En este trabajo se pretende explorar el alcance y las estrategias de la ciberviolencia antifeminista presente en la sección de comentarios de YouTube. Para responder a este objetivo principal se parte de un estudio de caso: los comentarios que acompañan el vídeo Why I'm... a feminist, publicado por la youtubera estadounidense Laci Green (2014). Sobre estos, se realiza un análisis de contenido cualitativo cuya interpretación toma como referencia la teoría defendida por Cole (2015) y basada en el modelo de retórica disciplinaria de Foucault (1975). De acuerdo con los resultados, el «insulto», el «sarcasmo», la «imposición», el «deseo de dañar», la «objetivación sexual», la "criminalización/difamación» y la "amenaza» (tanto general como explícitamente sexual) constituyen mecanismos de coacción aplicados sistemáticamente para silenciar a la mujer feminista. Paralelamente, la incomprensión del feminismo, es decir, la defensa de una versión errónea y estereotipada del mismo, representa un patrón común con elevado potencial para promover situaciones de ciberviolencia futuras. La progresiva normalización de la ciberviolencia contra la mujer y antifeminista requiere una respuesta urgente. Además de medidas de concienciación social, una regulación más rigurosa de la Red será imprescindible para que en el mundo virtual predomine el respeto y el empoderamiento, y no la violencia o la discriminación.

Palabras clave: internet; ciberfeminismo; violencia contra la mujer; sexismo; análisis de contenido; estrategias discursivas 
Abstract. Cyber violence on the Web: New forms of disciplinary rhetoric against feminism

Cyber violence against women and girls is emerging as a global problem. The increasing cases of feminist YouTubers suffering online harassment prove that this kind of aggression intensifies when the victim is a woman and a feminist. This paper aims to explore the scope and strategies of antifeminist cyber violence embedded within the YouTube comment section. In order to achieve the research goal, this work draws from a case study: the comments on the video Why I'm... a feminist, posted by the American YouTuber Laci Green (2014). A qualitative content analysis is undertaken of these comments, whose interpretation takes as a reference Cole's theory (2015) based on Foucault's model of disciplinary rhetoric (1975). According to the results, "insult", "sarcasm", "imposition", "wish to hurt", "sexual objectification", "criminalization/ defamation" and "threat" (both general and sexually explicit) constitute coercion mechanisms that are systematically applied to silence feminist women. Likewise, the misconception of feminism, that is, the advocacy of a mistaken and stereotyped version of this concept, represents a common pattern with high potential to promote future situations of cyber violence. The progressive normalization of cyber violence against women and girls requires an urgent response. In addition to measures of social awareness, a more rigorous online regulation would be essential for ensuring the predominance of respect and empowerment instead of violence and discrimination in the virtual world.

Keywords: Internet; cyberfeminism; violence against women; sexism; content analysis; discourse strategies

\section{Sumario}

1. Introducción

2. Mujeres online y la otra cara de Internet

3. Why I'm a... feminist, de la youtubera Laci Green: un estudio de caso
4. Resultados. El alcance de la ciberviolencia y sus estrategias

5. Discusión y conclusiones

Referencias bibliográficas

\section{Introducción}

El impacto de Internet y de las nuevas tecnologías de la información y de la comunicación, analizado desde una perspectiva de género, ha sido una cuestión frecuentemente desatendida por parte del sector académico. A pesar de que la relación entre ciencia, tecnología y género sea ampliamente significativa, su estudio ha sido en cierta medida residual, y se ha llegado a hablar de una «ceguera de género" (Perdomo, 2016). No obstante, existe suficiente evidencia científica acerca de la histórica y aún persistente brecha de género en el acceso a los principales medios digitales (Zoonen, 2002; Ferreira, 2015). Generalmente, la presencia de los hombres ha tendido a primar sobre la de las mujeres en el entorno virtual. En el caso de YouTube, por ejemplo, un $62 \%$ de usuarios son hombres, mientras que tan solo un 38\% son mujeres (Statista, 2016a). Si se tiene en cuenta la intensidad de uso de estos medios, en cambio, las distribuciones varían a favor de la mujer. A nivel global, las mujeres dedican una media 
de horas mensuales mayor $(4,53 \mathrm{~h})$ en comparación con los hombres $(3,77 \mathrm{~h})$ (Statista, 2016b). A pesar de tener un acceso más restringido, las mujeres parecen aprovechar en mayor medida que los hombres las posibilidades de comunicación y apoyo social que ofrece la Red (Zoonen, 2002; Joiner et al., 2012, Ferreira, 2015). Así mismo, los estudios y las estadísticas comparativas sugieren que la brecha de género en el entorno online se irá reduciendo cada vez más. Concretamente, el informe Women and the Web de Intel (2013) prevé que alrededor de 450 millones de nuevas usuarias podrían participar en el espacio virtual en los próximos tres años (citado en Naciones Unidas, 2015). Como en otros sectores donde la mujer ha permanecido históricamente invisibilizada, en el ámbito de Internet la creciente participación de las mujeres apunta a un proceso de «feminización de Internet» (Abraham et al., 2010).

Desde los años 70 hasta hoy día, la evolución del ciberfeminismo ha pasado por épocas diversas, transitando desde visiones tecnófobas y pesimistas (por ejemplo, ecofeminismo, neomarxismo) hasta posiciones más tecnófilas y utópicas (Haraway, 1991; Plant, 1997). El Manifesto Cyborg, escrito por Donna Haraway (1991), es un símbolo del feminismo que identifica la tecnología como medio transformador y liberador de situaciones de opresión. A través de la metáfora del cyborg, Haraway adjudica a las nuevas tecnologías la posibilidad de crear un espacio multidimensional donde los cuerpos se desvanezcan y los sujetos permanezcan bajo una redefinición constante y, por tanto, más allá del género. Plant (1997) también se muestra optimista ante las posibilidades que abre la tecnología digital imaginando una comunidad de mujeres que "tejerán» redes de apoyo. Sin embargo, Wajcman (2006), en su relectura crítica de las posturas de ambas autoras, advierte tanto de la transformación que ha sufrido la idea de cyborg, que ha pasado a ser una especie de fetiche al servicio de la ideología dominante, como de los riesgos de un nuevo esencialismo derivados de la posición de Plant. La posición tecnofeminista de Wajcman (2006) aboga por una postura más compleja y pragmática ante la tecnología que permita detectar no solo las posibilidades de libertad y horizontalidad que posibilita la Red, sino también las relaciones de poder según la «raza», el género, la clase social y/o la edad.

Actualmente, el movimiento ciberfeminista se ha multiplicado de tal manera que sería más correcto hablar de ciberfeminismo(s) (Daniels, 2009). A través de las redes sociales, las mujeres feministas comparten de forma masiva reflexiones, campañas, proyectos, para luchar y superar exclusiones y situaciones de desigualdad que van más allá del género e incluyen otras categorías de opresión (Perdomo, 2016). Esta clase de actuaciones es lo que De Miguel y Boix (2003) denominan ciberfeminismo social. De modo destacable, el video blogging o la publicación de vídeos en YouTube se está convirtiendo en un medio popular para la concienciación y educación sobre las realidades, problemáticas, o dilemas que encabezan las agendas de los movimientos feministas actuales. Youtuberas feministas como Laci Green, Marina Watanabe o Kat Blaque ejemplifican este tipo de activismo virtual. Para entender mejor las posibilidades de transformación social de estos sitios webs, resulta interesante la TEDx Talk 
realizada por Kat Lazo en 2013. Siguiendo su lema, Feminism isn't dead, it's gone viral!, Lazo explica cómo los portales webs y canales de YouTube feministas le abrieron las puertas al activismo y a la lucha por la igualdad de género en el campo tanto online como offline.

Sin embargo, Internet también plantea algunos de los mayores desafíos que ha de encarar el feminismo contemporáneo. Plataformas virtuales como YouTube también se pueden convertir en espacios dedicados a difundir la ciberviolencia y el discurso del odio contra la mujer. Diferentes investigaciones coinciden en que el lenguaje sarcástico, personalizado y violento encontrado en un gran número de redes sociales se dirige mayoritariamente a mujeres (Bartlett et al., 2014; West, 2014; Burke et al., 2015; Cole, 2015; Gurumurthy y Menon, 2009; Mathieu, 2011; Naciones Unidas, 2015, Hess, 2014). Esta clase de agresión online parece aumentar considerablemente cuando implica a una mujer que además se autoidentifica como feminista o promueve los principios del feminismo. Las crecientes noticias sobre escritoras, blogueras y youtuberas feministas que han sido víctimas de una violencia sistemática en el entorno virtual confirman esta dinámica (Blaque, 2016; West, 2014; Sánchez, 2016; Buzzfeed, 2015; TEDx Talk, 2012; McDonald, 2014 Taub, 2014; Watanabe, 2015 a,b) ). En el caso de YouTube, la ciberviolencia antifeminista que se concentra en la sección de comentarios llega a ser tan elevada que obliga a muchas youtuberas a solicitar su eliminación.

Ante esta situación, el presente trabajo tiene como objetivo general el análisis de la ciberviolencia antifeminista. Para ello se exploran el alcance y las estrategias de esta violencia a partir de un estudio de caso donde se analizan los comentarios asociados al vídeo Why I'm... a feminist, de la reconocida youtubera estadounidense Laci Green (2014). A la hora de analizar el caso seleccionado, se toma como referencia principal la teoría defendida por Cole (2015) y basada en el pensamiento de Foucault (1975). Esta defiende que la ciberviolencia pretende silenciar a la mujer feminista mediante la normalización de una violencia disfrazada por el sarcasmo.

\section{Mujeres online y la otra cara de Internet}

Aquello que «se manifiesta en el medio físico, se refleja necesariamente en el virtual y viceversa» (Pedraza et al., 2011: 74). Por tanto, inevitablemente, los sistemas de discriminación y opresión que estructuran el «mundo real» también se infiltran y reconfiguran el entorno virtual (Bartlett et al., 2014). De forma destacable, la desigualdad y la violencia de género que persisten en las relaciones humanas impregnan los espacios y las plataformas online. Más allá de las oportunidades de liberación feminista que han ofrecido los medios sociales digitales, estos también se han convertido en herramientas usadas sistemáticamente para estereotipar y dañar a la mujer (Bartlett et al., 2014; West, 2014; Burke et al., 2015; Cole, 2015; Gurumurthy y Menon, 2009; Mathieu, 2011; Naciones Unidas, 2015; Hess, 2014). De acuerdo con la Networked Intelligence for Development (2015), las mujeres son 27 veces más 
propensas a ser víctimas de abuso online que los hombres (citado en Naciones Unidas, 2015).

$\mathrm{Al}$ igual que otras formas de agresión offline, la ciberviolencia se ejerce como herramienta para controlar y tener poder sobre la mujer. En este caso, la violencia se perpetra en el espacio virtual mediante la difusión de vídeos, imágenes y/o comentarios degradantes que intentan atentar en contra de la dignidad o la vida de una persona (Pedraza et al., 2011). Como subraya el informe realizado por la organización Battered Women's Support Services (BWS) en el año 2014:

In many ways this violence is the same as other types of violence against women, whether it be physical abuse, or sexual assault, in that violence is wielded as a tool to control and have power over women, to maintain men's dominance over women as a class, and to reinforce patriarchal norms, roles and structures (West, 2014: 2).

En consecuencia, la llamada «ciberviolencia contra la mujer» está emergiendo como un problema global ligado al desarrollo y la difusión de Internet (íbid.). Alrededor del mundo, un total de 9 millones de mujeres ya han sufrido alguna forma de ciberviolencia seria desde la edad de los 15 años (Networked intelligence for development, citado en Naciones Unidas, 2015).

\subsection{Singularidades de la ciberviolencia contra la mujer}

Según West (2014), en el espacio virtual se dan tres características específicas que afectan decisivamente a esta tipología de violencia. La primera es el anonimato online. La posibilidad de ser un usuario o usuaria de manera encubierta y sin proveer apenas información personal se traduce directamente en una mayor impunidad para el agresor (Marlin-Bennett y Thornton, 2012: 498). El segundo rasgo característico es la facilidad y la accesibilidad a la información a gran escala. En contradicción con el primer punto, pero en sintonía con las paradojas y contradicciones ligadas al mundo online, Internet representa una auténtica fuente de información personal (Burke et. al., 2015). Por ejemplo, la participación en las redes sociales puede convertirse en una manera de perseguir y controlar los movimientos de una víctima potencial. Al mismo tiempo, el ciberespacio permite compartir información y material multimedia más allá de las fronteras y con un coste mínimo. Por tanto, la difusión de propaganda misógina o material ciberviolento en contra de la mujer puede resultar sorprendentemente fácil. Por último, el tercer aspecto a destacar es la permanencia digital, es decir, la dificultad asociada a eliminar material o información del entorno virtual. Junto con ello, es importante tener en cuenta que el ciberespacio es un lugar fuertemente simbolizado donde aquello publicado en referencia a una persona influye cada vez más en su reputación social y laboral (Pedraza et al., 2011). De este modo, es probable que el acto de odio o violencia dirigido hacia una persona vía Internet persista en la Red y tenga consecuencias a largo plazo (West, 2014: 2). 
De acuerdo con la terminología empleada en el informe de las Naciones Unidas (2015) en el que se habla de Cyber Violence Against Women and Girls, se ha optado por respetar el término de «ciberviolencia contra la mujer». Este último refuerza la idea ya defendida por True (2012) cuando señala:

Violence against women (VAW) occurs in a context of unequal gender relations. The concept of 'gender-based violence' (GBV) captures women's experience of violence due to unequal gender power relations but not exclusively, since men are also victims of violence due to gender stereotyping and denigration when they fail to live up to dominant forms of masculinity. Thus, GBV affects both men and women, whereas VAW embraces those violent acts that are primarily directed toward women by virtue of their gender and affect women disproportionately (True, 2012: 8).

Respecto a sus formas de manifestación, la ciberviolencia contra la mujer está relacionada con un conjunto de acciones muy diversas. En el informe más reciente de las Naciones Unidas (2015) en torno a esta problemática, se destacan seis procedimientos de agresión según categorización previa de la Violence against Women Learning Network (2013). Estos procedimientos (que también se pueden aplicar a otros colectivos) corresponden al hacking ${ }^{1}$ (acceder ilegalmente a sistemas informáticos externos con el propósito de adquirir o modificar información personal, así como difundir material que pueda denigrar o humillar a la víctima/s potencial/es); robo de identidad (asumir la identidad de otra persona sin consentimiento de la misma con el objetivo de acceder a información privada, ridiculizarla, crear documentos fraudulentos, etcétera); vigilancia (acechar o controlar las actividades y comportamientos presentes o pasados de una o más personas); ciberacoso (también ciberacecho o cyberstaling o ciberbullying) o spamming (contactar, molestar, amenazar, intimidar o aterrorizar de manera repetitiva y continuada a través de llamadas de teléfono, mensajes de texto, comentarios, etcétera); reclutamiento (captar víctimas potenciales mediante publicaciones, anuncios falsos, chats, etcétera); y la distribución maliciosa (manipular y difundir materiales ilegales y difamatorios, como fotografías íntimas o propaganda violenta, en relación con uno o varios sujetos).

A nivel no tan general, también existen diferentes terminologías formuladas específicamente para designar y distinguir entre diversos actos de ciberviolencia. El flaming y el outing serían claros ejemplos en este sentido. Por un lado, el flaming hace referencia a la acción de mandar mensajes provocadores e insultantes. El contenido de estos mensajes tiende a provocar emociones de tristeza, rabia, humillación, inseguridad (entre otras) al usuario/a que los

1. Cabe apuntar que la definición de hacking que aporta el informe de 2015 de las Naciones Unidas haría referencia exclusivamente al modus operandi de una tipología concreta de hacker: el cracker o blackhat hacker. A diferencia de la mayoría de hackers, los crackers se introducen en sistemas informáticos ajenos con fines ilícitos o criminales, por tanto, con el propósito de causar algún daño explícito (Gutiérrez, 2014). 
recibe (Sahin, 2012) ${ }^{2}$. «Por otro lado, el término outing describe la acción de compartir información y material multimedia embarazoso sobre otras personas sin haber obtenido previamente su consentimiento» (Burke et al., 2015). En el caso de que la difusión involucre fotografías o vídeos sexualmente explícitos, entonces es preferible hablar de revenge porn.

A pesar de que la violencia contra la mujer en el entorno virtual ha tendido a ser infraestudiada a nivel académico (Burke et al., 2015), existe suficiente evidencia empírica para confirmar su extrema relevancia y gravedad. Para empezar, la investigación que llevó a cabo la Universidad de Maryland (2006) resulta profundamente reveladora. En esta, se crearon cuentas de chat falsas bajo nombres de mujeres y de hombres con el objetivo de comparar la agresión y violencia recibida. Según los resultados, mientras que las cuentas etiquetadas a través de nombres de mujeres recibieron una media de 100 mensajes amenazantes y sexualmente explícitos por día, los usuarios con nombres de hombres tan solo recibieron una media de 3,7. Este sería un claro ejemplo de cómo las mujeres son atacadas online (y offline) por el mero hecho de ser mujeres (citado en Hess, 2014). Otro estudio paradigmático en este sentido fue el desarrollado por la Agencia de los Derechos Fundamentales de la Unión Europea (FRA) en el año 2014. De acuerdo con las respuestas a una encuesta a 42.000 mujeres provenientes de 28 Estados miembros de la Unión Europea, un 11\% de las mujeres había sufrido ciberacoso tras recibir mensajes ofensivos y sexualmente explícitos vía e-mail, SMS o redes sociales. Concretamente, "de las víctimas de acoso, un $23 \%$ señaló en la encuesta que tuvo que cambiar de dirección de correo electrónico o de número de teléfono después del caso más grave de acoso» (FRA, 2014: 13). Cabe añadir que la encuesta previa realizada por FRA en 2012 descubrió que el acecho cibernético perjudica particularmente a las mujeres jóvenes. «El riesgo de que las mujeres jóvenes de entre 18 y 29 años de edad sean objeto de amenazas e insinuaciones ofensivas en Internet es el doble que el de las mujeres de 40 a 49 años, y más del triple que las de 50 a 59 años» (ibíd.: 33). Bartow (2009) concluye que las blogueras son mucho más criticadas que los blogueros, sobre todo cuando no obedecen a los mandatos tradicionales de los roles de género. Además, también detectó un cariz diferente en el tipo de críticas: los ataques a las blogueras tenían a menudo un tono sexualmente violento. En esta línea, una investigación concluyente es la de Burke et al. (2015) con 293 mujeres norteamericanas mayores de edad (y una media de 24 años). La investigación sacó a la luz que, en los últimos 12 meses, el 19,9\% ( $\mathrm{n}=57)$ de las participantes habían recibido repetidamente un mensaje sexual obsceno no solicitado online de alguien que ellas no conocían, el $11,5 \%(\mathrm{n}=33)$ había recibido mensajes pornográficos, y casi una quinta parte $(19,2 \%, \mathrm{n}=55)$ había recibido repetidamente una solicitación

2. La definición de flamer guarda una gran similitud con aquella de trol (troll). El trol hace referencia a aquella persona que publica mensajes provocadores, irrelevantes o fuera de lugar en una comunidad en línea con la intención de molestar o provocar una respuesta emocional negativa entre los usuarios y las usuarias (Sahin, 2012). 
sexual en Internet también de alguien desconocido. En los últimos 12 meses, a más del $10 \%(12,5 \%, \mathrm{n}=36)$ les había llegado amenazas online de personas desconocidas. Finalmente, el 16,1\% $(n=46)$ de las participantes dijeron que habían sido hostigadas en la vida offline como resultado de ser acosadas online.

En referencia al impacto de esta violencia, los estudios confirman que esta tiene repercusiones físicas, psicológicas y socioeconómicas. De acuerdo con el informe de West (2014), el daño más común es el psicológico. Un 65\% de las mujeres encuestadas indicaron haber sufrido algún tipo de perjuicio psicológico, que incluía desde estados de ansiedad y baja autoestima (43\%) hasta casos más extremos como intenciones de suicidio y autodestrucción (10\%). Determinados actos de ciberviolencia, como la distribución maliciosa o el revenge porn, fueron muy propensos a generar daños a nivel laboral y económico, y concretamente un $13 \%$ de las mujeres encuestadas afirmaron haber percibido algún tipo de impacto negativo en su situación laboral. En definitiva, y de acuerdo con Citron (2009), el ciberacoso tiene graves consecuencias en el bienestar, la identidad, la dignidad y la subsistencia diaria de las mujeres.

\subsection{Las consecuencias de ser mujer y feminista en la Red}

La agresión online en contra de la mujer parece aumentar considerablemente cuando esta se encuentra involucrada o defiende públicamente proyectos feministas. De hecho, existen organizaciones misóginas que operan en el ciberespacio, como $A$ Voice for Men, dedicadas a atacar y despreciar el feminismo. En este sentido, el estudio realizado por West (2014) confirma esta dinámica: más de la mitad de las mujeres encuestadas habían sufrido algún tipo de abuso virtual por su condición de mujer y por ser miembro o participar en algún grupo feminista online. Así mismo, existen numerosos ejemplos de escritoras, blogueras y youtuberas feministas que han sido víctimas de una violencia sistemática en el entorno virtual (Goldberg, 2015). En el contexto estadounidense, el caso de Anita Sarkeesian destaca por la gran repercusión mediática que generó. La creadora del canal de YouTube Feminist Freqüency tuvo que enfrentarse a una campaña misógina masiva cuando esta inició su proyecto centrado en la deconstrucción de los videojuegos desde una perspectiva de género. Las redes sociales se inundaron de agresiones verbales, amenazas de violación y muerte dirigidas a Sarkeesian, su dirección y teléfonos personales fueron difundidos online, e incluso se llegaron a crear videojuegos donde se simulaba que esta era violada y agredida físicamente (TEDx Talks, 2012). Otras voces colaboradoras de sitios web feministas también han confirmado en múltiples ocasiones el elevado volumen de e-mails y comentarios ofensivos que reciben a diario. Por ejemplo, Jessica Valenti, periodista y fundadora del blog Feministing, explicó en The Washington Post el acoso continuado que sufren las escritoras feministas en el mundo online y las consecuencias que este puede llegar a tener tanto a nivel psicológico y emocional como físico (McDonald, 2014). En una línea similar, una de las editoras voluntarias de Feministing expuso en una entrevista ${ }^{3}$ (2009) lo siguiente:

3. La entrevista fue realizada por Stephanie E. Mathieu en 2009. 
I definitely think that women especially deal with comments about their appearance. Video blogging is a whole new level in terms of putting yourself out there, and if people don't like what you have to say, and there's even a tiny little thumbnail photo of you, every other comment will be like "you're hot, wanna f---?", "You're ugly, you suck»... Anyone who has been writing online and openly as a feminist for four years, like myself, is pretty much just used to it. That's just the way it is (citado en Mathieu, 2011: 13).

Paralelamente, cuando las entidades que gestionan las redes sociales no responden ante tal situación de violencia, es posible ver hasta qué punto la misoginia y otras formas de opresión impregnan los espacios virtuales. Este sería el caso de la bloguera Desiré Bela-Lobedde, quien, tras publicar su vídeo en YouTube Ser mujer negra en España (2013), recibió diversos comentarios incitadores al odio racista y machista (Sánchez, 2016). A pesar de que BelaLobedde denunció e informó sobre el suceso a YouTube, el sitio web le respondió afirmando que aquellos comentarios no infringían sus propias normativas. Esta respuesta ha conducido a que la bloguera catalana, junto con la Red Española de Inmigración, realice una denuncia en contra de YouTube y los usuarios implicados. Una de las consecuencias de esta denuncia ha sido la eliminación de todos los comentarios que acompañan al vídeo correspondiente. Ciertamente, de manera frecuente las youtuberas se ven obligadas a solicitar la eliminación de la sección de comentarios ligados a sus vídeos, especialmente de aquellos que tratan de manera específica el tema del feminismo y/o cuestiones relacionadas. Por ejemplo, este sería el caso de Anita Sarkeesian (2016), Francesca Ramsey (2012), Marina Watanabe (2014) o Kat Blaque (2014). Concretamente, Watanabe y Blaque han publicado vídeos donde abordan esta problemática. En su vídeo titulado Why I delete comments, Watanabe (2015a) responde que «every single day I am receiving sexist comments... and for my own mental health I delete those comments». Simultáneamente, Blaque (2016), en su vídeo Don't read the comments, sostiene con relación a la sección de comentarios que "while it could be a place for engaging conversation and enlightening debate, it's often a place where hope in humanity is quickly lost... times have changed and there is an entire culture dedicated to wasting your time and attempting to upset you online».

Finalmente, para entender el trasfondo de toda esta violencia perpetrada contra la mujer, especialmente sobre aquella que se visibiliza como feminista, resulta interesante atender a la reflexión de Cole (2015). La autora asocia la hostilidad antifeminista virtual con el concepto de retórica disciplinaria acuñado por Foucault (1975). En palabras del filósofo: «El ejercicio de la disciplina supone un dispositivo que coacciona por el juego de la mirada; un aparato en el que las técnicas que permiten ver inducen efectos de poder y donde, de rechazo, los medios de coerción hacen claramente visibles aquellos sobre quienes se aplican» (Foucault, 1975: 175).

Para Cole (2015), la retórica disciplinaria se aplica sistemáticamente sobre aquellas mujeres feministas que participan en la esfera pública. El mecanismo 
primario de disciplina, la coacción, se realiza a través de una violencia que es proyectada en sus cuerpos. Como afirma Foucault (1975: 188), «la penalidad perfecta que atraviesa todos los puntos, y controla todos los instantes de las instituciones disciplinarias, compara, diferencia, jerarquiza, homogeniza, excluye. En una palabra, normaliza». Aquí la coacción se normaliza y naturaliza a partir de comentarios, imágenes, anuncios, que promueven la violación del cuerpo femenino. En conexión con este pensamiento, y en línea con la denuncia ya clásica de Faludi (1991), Filipovic (2007) afirma:

These kinds of sexualized insults reflect attempts to put women in their place, just as rape threats attempt to keep women fearful in an effort to relegate them to the domestic sphere...Sexual assault and, to a greater degree, the very threat of sexual assault, is used to keep women fearful, and to deter them from public participation... Men are generally attacked for their ideas or their behavior; when Internet aggressors go after women, they go straight between the legs... They remind women in general that the punishment for displeasing men - even anonymous men online- will be at best sexually insulting, and at worst sexually violent (Filipovic, 2007: 302-303).

Además, el tono humorístico o sarcástico tiende a usarse como herramienta para convertir este acto de violencia en algo socialmente aceptable. Un ejemplo de ello es la publicación masiva de comentarios sobre la violación de la mujer donde a su vez se incluyen emoticonos, bromas, acrónimos o memes como \#rapeface. Como subraya Cole, "when trolls post comments such as 'You should be raped! LOL' they seek to discipline feminists into silence while simultaneously proclaiming that their version of rape is somehow funny, somehow safe, and somehow different» (Cole, 2015: 357). Dicho esto, se puede constatar que aquellas mujeres que expresan en sus trabajos reflexiones, opiniones a favor del feminismo no solo se enfrentan a un desprecio o desacuerdo online, sino que también han de encarar una violencia sexual disfrazada por el uso del sarcasmo y el humor (Mathieu, 2011: 15).

Partiendo del contexto anterior, el presente trabajo se plantea la pregunta general sobre cuáles son las estrategias de violencia que se adoptan en el ciberespacio. Para ello, y más concretamente, nos proponemos el análisis del tipo de estrategias discursivas de los comentarios al vídeo Why I'm a... feminist, publicado y protagonizado por la conocida youtubera y bloguera estadounidense Laci Green (2014).

\section{Why I'm a... feminist, de la youtubera Laci Green: un estudio de caso}

El análisis empírico realizado en esta segunda sección del trabajo pretende contribuir a la comprensión de la ciberviolencia antifeminista desencadenada en la sección de comentarios de YouTube, explorando su alcance y estrategias. Para llevar a cabo estos propósitos, el trabajo parte de un estudio de caso centrado en los comentarios que acompañan al vídeo Why I'm a... feminist, publicado el 23 de abril de 2014 y protagonizado por la conocida youtubera y bloguera 
estadounidense Laci Green. La elección se apoya en dos razones principales. La primera, su elevada difusión y repercusión. Para empezar, es importante tener en cuenta que Laci Green ha sido reconocida como una de las 30 personas más influyentes en el mundo de Internet (Time, 2016). Su canal de YouTube, Sex plus, posee más de un millón de suscripciones y visualizaciones en los 196 países, y ha sido galardonado en diversas ocasiones ${ }^{4}$. A través de sus vídeos, Green explora cuestiones relacionadas con la sexualidad, el género, la imagen corporal y la justicia social. Concretamente, el canal busca promover la educación sexual y, con ello, prevenir situaciones de violencia sexual, haciendo especial hincapié en la importancia del consentimiento. Según los datos aportados por la página web oficial de Laci Green (2018), «5,000,000 young adults tune in to Sex Plus on YouTube every month, making Laci one of the most popular sexual violence prevention advocates and sex educators accessed outside the classroom». Dentro de su lista de reproducción dedicada al feminismo, su vídeo Why I’m... a feministı ha obtenido sin duda la mayor difusión, y ha llegado a más de 3 millones de visualizaciones y contando con más de 80.000 comentarios $^{5}$. Al margen de YouTube, este vídeo también ha sido compartido masivamente en las redes sociales, tanto en blogs liberales (por ejemplo, The Huffpost Women) como en fórums misóginos (por ejemplo, A Voice for Men), con el objetivo de perjudicar la imagen y la credibilidad de Green. En referencia a su contenido, este expone en apenas cinco minutos algunas de las muchas razones por las cuales la youtubera es feminista. Concretamente, Green aborda la importancia del feminismo a partir de experiencias personales, casos concretos, estudios y estadísticas oficiales que reflejan la desigualdad y la violencia de género que persisten en las sociedades actuales. La segunda razón por la que se ha seleccionado este caso tiene que ver con la visibilización pública de los comentarios. Al contrario que otras youtuberas expuestas anteriormente ${ }^{6}$, Green no ha declarado haber eliminado los comentarios asociados a sus vídeos a pesar de que sí haya confirmado en repetidas ocasiones la agresión que recibe a través de estos (Marusic, 2015).

\subsection{Criterios de selección de la muestra de análisis}

La unidad de análisis es cada uno de los comentarios principales (Top level comments) que acompañan el vídeo de YouTube Why I'm a... feminist, publicado por Laci Green en el mes de abril de 2014. Con la denominación de comentarios principales, se hace referencia únicamente a aquellos que no responden a un comentario anterior. De acuerdo con ello, el 5 de abril de 2016 (fecha en la que

4. Premios concedidos a Sex plus: Streamy Award Winner, Science, and Education; YouTube Honors 2011-2013; 1,000,000 Subscriber Award. (LaciGreenTV, 2018).

5. Las visualizaciones y los comentarios recopilados corresponden a la fecha de 5 de junio de 2016, y tienen en cuenta tanto los comentarios principales como secundarios.

6. Ciertamente, en un principio se había considerado comparar los comentarios que reciben diferentes youtuberas feministas populares (principalmente Watanabe, Blaque y Green), pero se desestimó esta opción ya que estas últimas eliminaban los comentarios ofensivos. 
arranca la presente investigación), la población o universo fue de 29,357 comentarios principales (lo que reafirma lo señalado en el apartado anterior respecto a su amplia repercusión y difusión). Con relación a la técnica de muestreo, se ha delimitado un intervalo temporal que incluye todos los comentarios principales publicados desde el 10 de abril de 2016 hasta el 30 de abril del mismo año, lo que equivale finalmente a 850 comentarios principales analizados. La elección de esta reducida franja temporal se ha basado en la saturación de la información: a medida que se recopilaban datos, los resultados se repetían y no aportaban información adicional. Para evitar posibles sesgos, se comprobó que los comentarios correspondieran a autores distintos. Durante la recolección de datos, se fijó como metodología de control un límite de 10 comentarios por usuario/ autor. Es decir, se comprobó si cada usuario/autor había escrito más de 10 comentarios en el vídeo analizado para considerar su influencia en los resultados.

Se han adoptado dos criterios de invisibilización para preservar el anonimato de los autores de los comentarios: en primer lugar, no se han revelado los nombres de usuario que estos mantienen en YouTube y, en segundo lugar, los comentarios citados se han traducido del inglés al castellano (excepto en el caso de los insultos). En referencia a esta última cuestión, es necesario tener en cuenta que los ejemplos de comentarios expuestos en la sección de resultados han sido citados literalmente para reflejar más objetivamente el alcance y las características de la ciberviolencia que reciben las youtuberas feministas. No obstante, y dependiendo del contexto, en el caso de comentarios que se consideran demasiado ofensivos se ha aplicado el uso de los asteriscos.

\subsection{Metodología de análisis}

Una vez obtenida la muestra, el método seleccionado para describirla e interpretarla ha sido el análisis de contenido cualitativo. De acuerdo con Hsieh \& Shannon (2005), «qualitative content analysis is defined as a research method for the subjective interpretation of the content of text data through the systematic classification process of coding and identifying themes or patterns» (p. 1278). Este método va más allá del simple recuento de determinadas palabras o categorías del texto, y posibilita una interpretación del contenido subyacente (Mayring, 2000). En este trabajo, el análisis de contenido cualitativo se ha realizado a través de la combinación de un enfoque tanto deductivo como inductivo. Es decir, mientras que algunas categorías derivan de estudios previos consultados (Mathieu, 2011; Naciones Unidas, 2015; West, 2014; IHeartMob, 2016, Take Back the Tech, 2016), otras se han construido a partir del análisis de la muestra específica analizada. Tal y como afirman Cho \& Lee (2014), «one unique characteristic of qualitative content analysis is the flexibility of using inductive or deductive approaches or a combination of both approaches in data analysis» (p. 4). En definitiva, la codificación ha dado lugar a un proceso de análisis de datos circular, interactivo y progresivo, donde constantemente se ha comparado y revisado la validez de cada una de las categorías. 
En la tabla 1 se especifican las categorías de análisis para el conjunto de estrategias de ciberviolencia empleadas en los comentarios principales (Top level comments) del vídeo de YouTube Why I'm a... feminis» (Laci Green, 2014).

Por último, cabe recordar que un comentario es catalogado como ciberviolento cuando aplica al menos una de las estrategias de ciberviolencia categorizadas anteriormente. Dependiendo de su naturaleza, cada comentario puede incluirse en una o más categorías de análisis.

Tabla 1. Categorías de análisis de las estrategias de ciberviolencia.

\begin{tabular}{ll}
\hline Categoría de análisis & Definición \\
\hline Insulto & El usuario/a usa un lenguaje ofensivo, abusivo y vulgar dirigido \\
& sistemáticamente a una persona o grupos de personas. Ejemplo: \\
& «idiota» («idiot»), «zorra» («cunt»), «feminazi», etcétera. \\
\hline Sarcasmo & El usuario/a expone un dicho irónico y cruel para ridiculizar, \\
& humillar o insultar a una persona o grupos de personas. Apela \\
& al humor pero de manera malintencionada y con el objetivo de \\
& causar algún daño. Ejemplo: «No soy feminista porque ciertamen- \\
& te tengo cerebro». Incluye emoticonos, acrónimos, hashtags o \\
& memes, por ejemplo, «\#fuckfeminazis», «LOL», etcétera.
\end{tabular}

Imposición

El usuario/a ordena que se realice o deje de realizar una o varias acciones con el objetivo de denigrar, estigmatizar o silenciar a una persona o grupos de personas. La oración adquiere un tono imperativo o exclamativo. Ejemplo: «cállate», "vuelve a la cocina», etcétera.

Deseo de dañar

El usuario/a se centra en el deseo de provocar daño de manera explícita en otras personas. Ejemplo: «Ojalá te mueras». También hace referencia a cuando el usuario/a quiere hacerse daño a sí mismo con el objetivo de culpabilizar a una o varias personas. Ejemplo: «Necesito beber lejía».

\begin{tabular}{ll}
\hline Objetivación sexual & El usuario/a mira, trata y considera a una persona o grupos de \\
& personas como objetos usados únicamente para el placer sexual \\
& (masculino). Su cuerpo en general o determinadas partes del \\
& mismo se convierten en el tema central del comentario. Ejemplo: \\
& «Debe enseñar más el escote», «Está muy buena», etcétera.
\end{tabular}

Criminalización y difamación El usuario/a etiqueta a una persona o grupos de personas como criminales (por ejemplo, como asesinos/a, violadores/a, etcétera) o difunde información falsa sobre determinados sujetos (por ejemplo, en relación a su familia, pasado, etcétera).

Amenaza a nivel general El usuario/a realiza una declaración donde advierte de la intención de causar un dolor, daño, perjuicio o cualquier otra acción hostil a una persona o grupos de personas. Ejemplo: amenazas de muerte, de violación, de secuestro, de difusión de material difamatorio, etcétera.

\begin{tabular}{ll}
\hline Amenaza sexual & El usuario/a hace una declaración donde advierte de la intención \\
de violentar sexualmente a una persona o grupos de personas. & Ejemplo: amenazas de violación, de tocamientos, etcétera.
\end{tabular}

Fuente: elaboración propia. 


\subsection{Limitaciones metodológicas}

La investigación en el ámbito de la comunicación ha incorporado con fuerza el estudio de la comunicación online (Salmons, 2016), ya sea el estudio de blogs, microblogs, mensajes electrónicos, foros, chats, etcétera. El carácter específico de este tipo de comunicación (el usuario puede falsear su identidad, edad, orientación sexual, etcétera), así como la obligación de anonimizar los comentarios, supone una limitación frente a otras formas de investigación más tradicionales en las que quedan claras las variables sociodemográficas de los sujetos de la muestra. Sin embargo, y tal y como defienden Fielding, Lee y Blank (2008), como aspecto positivo a tener en cuenta se da una mayor libertad para compartir ideas y juicios, y la investigación online se interesa en el estudio de estos discursos espontáneos.

\section{Resultados. El alcance de la ciberviolencia y sus estrategias}

Los resultados demuestran que el alcance de la ciberviolencia en la sección de comentarios del vídeo Why I'm... a feminist ha sido elevado: de los 850 comentarios analizados, 478 se han clasificados como ciberviolentos. Es decir, más de la mitad de la muestra $(56,2 \%)$ contiene comentarios que aplican al menos una de las estrategias de ciberviolencia categorizadas durante el proceso de operacionalización. Para obtener una imagen global de la problemática se puede observar el gráfico $1^{7}$, donde se exponen y comparan las frecuencias de cada una de las estrategias identificadas.

A continuación se presentan los datos cualitativos correspondientes a cada una de las categorías de análisis.

\subsection{Insultos}

El insulto conforma la estrategia de ciberviolencia más común: más de la mitad de los comentarios ciberviolentos analizados incluyen insultos dirigidos primordialmente a la youtubera y a las mujeres en general (feministas y no feministas) $(\mathrm{n}=264)$. Para empezar es importante tener en cuenta que muchas palabras que se aplican como insulto no tendrían que serlo y derivan de una situación de discriminación social previa. En la muestra analizada la naturaleza de los insultos es muy diversa: por un lado, se declaran insultos orientados a atacar su estado mental, capacidad o racionalidad — «estúpidas» («stupid»), «retrasadas» («retar-

7. Como se apunta en la metodología, cada comentario es catalogado como ciberviolento cuando aplica al menos una de las estrategias de ciberviolencia categorizadas anteriormente; así que, dependiendo de su naturaleza, cada comentario puede incluirse en una o más categorías de análisis. Por ejemplo, un comentario podría formar parte de la categoría del insulto y, al mismo tiempo, de la del sarcasmo o de la objetivación sexual. Este hecho provoca que cuando se calculan los porcentajes (Insulto: 55,2\%; Sarcasmo: 47,1\%; Imposición: 18\%; Deseo de dañar: $15,1 \%$; Objetivación sexual: $9 \%$; Criminalización y difamación: 6,3\%; Amenaza general: 3\%; y Amenaza sexual: 0,1\%) su suma global no sea 100 . 
Gráfico 1. Estrategias de ciberviolencia

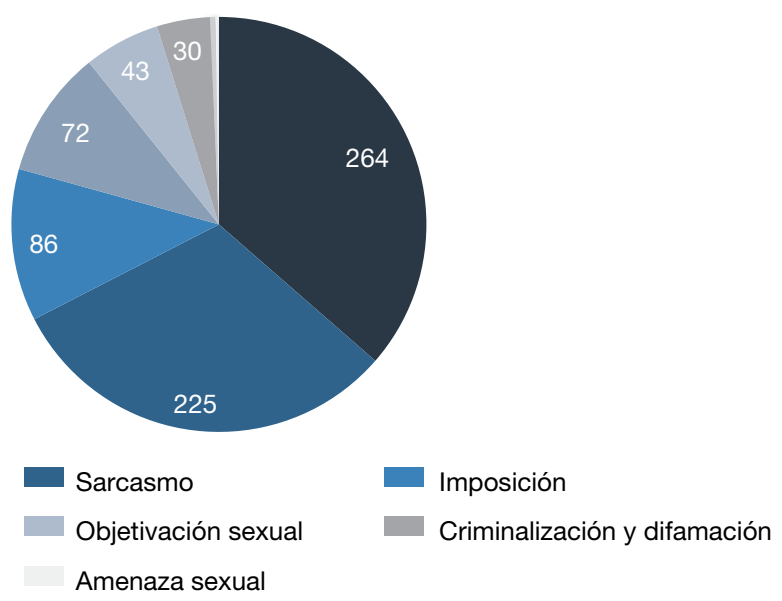

Fuente: elaboración propia.

ded»), «enfermas mentales» («mental disorder»), «lunáticas» («lunatic»), etcétera-; por otro lado, se realizan otros insultos dirigidos a infravalorar su aspecto físico — «horrorosas» («ugly»), «asquerosas» ("gross»), «gordas» («fat»)—. Simultáneamente, para enfatizar estos insultos también se las compara frecuentemente con animales no humanos de gran volumen, como las «vacas» («cows») o las «ballenas» («whales»). No obstante, en la mayoría de casos los insultos relacionados con su estado mental y físico se combinan y aparecen junto a otras palabras peyorativas como «zorra» («cunt»), "guarra» («slut») o «puta» («bitch»). El siguiente comentario ejemplifica esta dinámica común: «Eres insistentemente una estúpida $\mathrm{z}^{* * *} \mathrm{a}$ que solo quiere ayudar a su demente religión y robar dinero de los hombres...». Algunos usuarios aprovechan la sección de comentarios para insultar a otras mujeres que conocen o para reafirmar estereotipos sexistas de género. Concretamente, estos últimos realizan declaraciones como: «Para ser honesto muchas de las chicas de mi escuela son unas completas $\mathrm{p}^{* * *} \mathrm{~s}$. Todo lo que hacen es insultar a los profesores, hablar por las espaldas, insultarse entre ellas...». Más allá de esta clase de insultos, también se cuestiona la condición humana de las mujeres feministas mediante expresiones como «basura humana» ("human garbage»). Para referirse a estas últimas, los usuarios también usan frecuentemente el insulto "feminazi», así como las comparaciones con enfermedades malignas. Por último, la palabra "gay» o "lesbiana» ("lesbian») también aparece usada como insulto dirigido en la mayor parte de los casos a la youtubera.

\subsection{Sarcasmos}

El uso de comentarios irónicos con el fin de humillar, ridiculizar e insultar aparece como la segunda estrategia de ciberviolencia más frecuente. 
Específicamente, un total de 225 comentarios ciberviolentos emplean el sarcasmo. A nivel lingüístico, esta clase de comentarios suelen apoderarse de numerosos recursos como expresiones exageradas, preguntas retóricas, metáforas, palabras escritas en mayúscula, hashtags (por ejemplo, «\#fuckfeminazis»), memes (por ejemplo, «Know your place, trash»), acrónimos (por ejemplo, «LOL») y emoticonos (por ejemplo, :). . Una gran mayoría de usuarios apela al sarcasmo para arremeter en contra de la youtubera en cuestión. Por una parte, a través de la burla pretenden negar que cualquier persona pueda sentirse atraída físicamente por la protagonista del vídeo. Concretamente, se realizan comentarios despectivos sobre su cara, axilas o pechos. Al mismo tiempo, se intenta atentar en contra de su libertad y autonomía personal con frases como: «¿Quién te dejó salir de la cocina? Voy a llamar a tu hombre para controlarte, que te ponga una correa o algo». Cabe añadir que el sarcasmo también se usa para denigrar determinadas orientaciones sexuales, así como a los sujetos pertenecientes a otras especies. Los siguientes ejemplos son una prueba de ello: «... Me di cuenta de que eres un gay retrasado al igual que todas las otras feministas»o "Las vacas pueden hablar ahora». Por otra parte, los usuarios aprovechan el tema central del vídeo y su título para responder irónicamente al "porqué no son feministas». La violencia antifeminista resulta palpable en frases sarcásticas como: "¿Qué es el feminismo? Hmm, nada que una inyección letal no pueda fijar». En determinados comentarios, la autora del vídeo se convierte en la excusa oportuna para alimentar el antifeminismo: «Necesitaba una cara a la que odiar para este grupo de gente. Gracias, Laci». Finalmente, un subgrupo de comentarios sarcásticos manifiesta un claro rechazo hacia aquellas personas que viven en Oriente Medio o que se identifican como musulmanas. Estos colectivos son frecuentemente objeto de acusaciones relacionadas con el machismo y el fundamentalismo religioso.

\subsection{Imposiciones}

A pesar de que la imposición representa la tercera estrategia más común $(\mathrm{n}=86)$, su frecuencia es relativamente menor en comparación con aquella perteneciente a los insultos o sarcasmos. De forma general, la imposición incluye recursos lingüísticos particulares como oraciones de tipología tanto imperativa como exclamativa o palabras escritas en mayúscula. Como primer punto, la imposición que se repite más veces es aquella que confina a la mujer en el entorno doméstico. Constantemente, se le ordena a la autora del vídeo que vuelva a la cocina y esté al servicio del hombre (por ejemplo, «Vuelve a la cocina»). En algunas ocasiones el usuario además exige que Green abandone su trabajo en el mundo virtual. El siguiente comentario confirma la dinámica anterior: «... Tan solo estás perjudicando a las mujeres hablando de esta $\mathrm{m}^{* * *}$ da. Deja YouTube y vuelve a la cocina...». Para enfatizar la situación de inferioridad social que otorgan a las mujeres, los usuarios también utilizan repetidamente el meme "Know your place, trash». Al igual que en las anteriores estrategias, las órdenes también pretenden desacreditar el nivel de racionalidad 
o capacidad mental de la youtubera y de las feministas en general. En este caso, su supuesta «irracionalidad» o «incapacidad» se aprovecha para exigir que abandonen las tareas de concienciación y educación feminista. Por otro lado, muchos comentarios incluyen imposiciones que directamente ordenan a la youtubera que termine con su vida. En este sentido, se usa repetitivamente el término kill yourself. Este tipo de comportamiento también se refleja en frases más extensas y específicas donde le piden que se autodestruya o se provoque determinadas enfermedades. Como último punto, también es posible identificar comentarios impositivos dedicados a objetivar y victimizar sexualmente a la youtubera. A modo de ejemplo, un usuario declara lo siguiente: «Deja de llamar la atención, $\mathrm{g}^{* * *}$ ra».

\subsection{Deseos de dañar}

Partiendo de esta estrategia, el usuario se centra en el deseo de provocar daño de manera explícita. Esta se aplica en 72 comentarios y, por tanto, mantiene una frecuencia de uso similar a la imposición. A nivel cualitativo, se han encontrado tres subcategorías relacionadas con el deseo de dañar: la agresión directa, la agresión indirecta y el daño a uno mismo. En la primera subcategoría, la agresión directa, se han incluido aquellos comentarios donde el usuario ha expresado de manera explícita su deseo de que la youtubera sufra algún daño. Dentro de estos deseos, el sujeto directo que lleva a cabo el daño puede ser tanto la misma autora del vídeo (por ejemplo, «Incluso mi abuelo quiere que te suicides») como terceras personas o el mismo usuario (por ejemplo, "Quiero atarla a una silla darle ha*** zos con un martillo»). La violación y la agresión sexual son a menudo anhelos declarados por parte de estos usuarios. Con relación a la segunda subcategoría, la agresión indirecta consiste en todos aquellos comentarios donde indirectamente se desea dañar a Green. A modo de ejemplo, esta alternativa incluye afirmaciones como: «Pegué a mi mujer extrafuerte después de ver esto». En este último ejemplo, se puede observar que también salen a la luz casos de violencia doméstica a través de la sección de comentarios. Por último, el daño a uno mismo hace referencia a aquellas situaciones donde el usuario exclama querer hacerse daño a sí mismo con el objetivo de culpabilizar a la autora del vídeo. Representan esta última subcategoría ejemplos como: «Visto un minuto de esta $\mathrm{m}^{* * *}$ da y ahora necesito ir a beber una jarra de lejía».

\subsection{Objetivaciones sexuales}

Un total de 43 comentarios se dedican a objetivar sexualmente a la autora del vídeo y, en menor medida, a las mujeres tanto feministas como no feministas. A nivel cualitativo, un gran número de comentarios se focalizan en evaluar determinadas partes del cuerpo de la youtubera, como los pechos o el trasero. En algunos casos, esta clase de comentarios omiten cualquier tipo de observación sobre el contenido del vídeo, incluyendo expresiones como «Bonitas 
tetas». En otros, los usuarios además de objetivar también infravaloran y anulan por completo el trabajo de la autora del vídeo escribiendo frases como «... No tengo ni idea sobre lo que está balbuceando (a quién le importa) pero ella debe enseñar más el escote». De hecho, diversas declaraciones directamente reconocen a las mujeres como simplemente objetos sexuales "creados» para satisfacer el deseo sexual masculino. En último lugar, otra subcategoría de comentarios que adoptan esta estrategia son aquellos relacionados con el acto sexual en sí mismo. Entre estos comentarios, la mayoría hace referencia a expresiones vulgares relacionadas con la sumisión de las mujeres feministas frente a los órganos genitales masculinos, particularmente hacen referencia a felaciones. Otros, en cambio, plantean irónicamente situaciones de posible abuso sexual. El siguiente comentario sería un ejemplo de ello: «Buscando una persona joven confusa con un género fluido con genitales femeninos para tener sexo caliente, patriarcal, odioso y posiblemente altamente traumático».

\subsection{Criminalizaciones y difamaciones}

La estrategia de criminalización y difamación resulta poco común, dado que es aplicada en tan solo 30 comentarios. De manera general, estos actos de violencia atentan contra la reputación de las mujeres feministas y les adjudican crímenes y acciones reprobables. Resulta destacable la asociación que se realiza entre el feminismo y el nazismo a través del mismo término feminazi, así como de otras muchas comparaciones. De nuevo, la youtubera se convierte en la diana donde dirigir toda esta clase de acusaciones y ataques. En este sentido, se pueden citar los siguientes comentarios: «No soy feminista. Venid a mi armada feminazi comandada por la führer suprema Laci» o «La igualdad de género en las mentes feminazis es una dominación y una esclavitud. Y, si tu padre fue una mala persona, entonces esto significa que tu madre es una guarra que se f***ó a muchos chicos hasta que la mantuvieron». En este último comentario, se demuestra como también se difunde información denigrante sobre los familiares de la youtubera. Ciertamente, los amigos de Green también son atacados, a la vez que se difama sobre su relación sentimental con otros chicos. Por otro lado, los usuarios también publican comentarios donde acusan de violación a la protagonista del vídeo. Para acabar, la difamación también incluye comentarios sobre profesiones falsas relacionadas con la youtubera (por ejemplo, actriz porno).

\subsection{Amenazas generales y sexuales}

Mientras que en la amenaza general el usuario realiza una declaración donde advierte de la intención de causar un dolor, daño, perjuicio o cualquier otra acción hostil a una persona o grupo de personas, en la amenaza sexual este último se focaliza en la intención de violentar sexualmente a una persona o grupos de personas. En base a ello, se puede corroborar que las amenazas directas tanto a nivel general como sexual se han convertido en la estrategia menos aplicada 
en la muestra. Únicamente se han encontrado tres amenazas generales, dos de las cuales también se ha clasificado como sexuales. Como ejemplo de amenaza exclusivamente general, se puede citar la siguiente: «Voy a mirar imágenes degradantes de mujeres y votar a Donald Trump». Con relación a la amenaza sexual, es necesario enfatizar un comentario donde un usuario advierte a la youtubera de «que la asesinará y, después, violará». En este último caso se ha comprobado que 10 personas pusieron «me gusta» al comentario y 35 lo respondieron no en señal de desacuerdo sino de apoyo.

\subsection{Más allá de la ciberviolencia explícita: la incomprensión del feminismo}

Un dato no previsto en los planteamientos iniciales de la investigación tuvo que ver con aquellos comentarios que no podían ser incluidos en las categorías de ciberviolencia pero que reflejaban una incomprensión clara de los principios y objetivos del feminismo. Puesto que se registraron un total de 212 comentarios (lo que representa un $25 \%$ de la muestra), se optó por incluirlos en la investigación. Esta visión errónea está ligada íntimamente a la creencia de determinados prejuicios y estereotipos negativos en torno a los movimientos feministas. Por ejemplo, frecuentemente se retrata a las mujeres feministas como personas obsesionadas con un «victimismo y una opresión ilusoria». No obstante, el prejuicio más común de la muestra es aquel que considera el feminismo como sinónimo de misandria, invocando la supremacía de la mujer sobre el hombre. Así, se intenta dar a entender que el feminismo va en contra de cualquier tipo de igualitarismo. La siguiente declaración ejemplifica esta creencia: «... ¿ Sabes qué es más importante que el feminismo? ¡Los derechos humanos! ¡Lucha por tus derechos porque eres un ser humano y no porque perteneces a un género particular!». La búsqueda de la misandria la justifican mediante un odio «inherente» que las feministas sienten por los hombres, particularmente por aquellos heterosexuales y provenientes de sociedades «occidentales».

Paralelamente, la incomprensión del feminismo queda retratada en los múltiples comentarios centrados en reclamar la atención de las preocupaciones de los hombres, particularmente de su situación como «víctimas de la sociedad». En este sentido, se pueden encontrar comentarios como: «Típico feminismo... No habla de lo que los hombres sufren en la sociedad»o «iCuándo el mundo será seguro para los hombres?». Los usuarios que han publicado esta clase de comentarios han tendido a escribir explicaciones más extensas en comparación con el resto, incorporando ejemplos, vivencias personales y datos estadísticos. Por ejemplo, la «victimización masculina» se centra en mostrar que los hombres resultan más perjudicados en el mundo laboral en comparación con las mujeres al tener que "trabajar más horas y en sectores más peligrosos». Junto con ello, los usuarios preguntan continuamente a la youtubera por qué no incluye en su discurso los «múltiples casos de abusos sexuales y violaciones masculinas que ocurren particularmente en las prisiones». Bajo la misma retórica, se llega a culpabilizar a las mujeres en situaciones de violencia de género. Por ejemplo, un usuario defiende que «muchos casos de violación femenina podrían 
ser evitados si no se vistieran con ropas tan marcadas, o se emborracharan, o cualquier otra cosa que pudiera ser una razón...».

Finalmente, la incomprensión del feminismo también puede ser identificada en aquellos comentarios que consideran que la desigualdad de género es un hecho del pasado o que únicamente ocurre en sociedades alejadas del «mundo occidental». Por un lado, estos asumen que las mujeres ostentan el mismo poder que los hombres y que, por tanto, no se encuentran en una situación de opresión. Por otro lado, exponen que el feminismo debe preocuparse de problemas «reales» que ocurren en otros países «del tercer mundo» o ubicados en Oriente Medio. Para entender mejor está posición compartida por muchos usuarios, se puede citar la siguiente declaración: «Existen millones de mujeres migrantes que han sido desplazadas de sus países y no tienen ninguna comida para dar a sus hijos y te estás quejando de que te piropean. Confía en mí, no tienes que preocuparte por esto».

Los resultados mostrados en esta sección sirven de ejemplo del reforzamiento de las posiciones «neosexistas» de las que advertían Moya y Expósito (2001) y que para Osborne (2009) representan la manera que tienen algunos hombres de justificar la violencia contra las mujeres precisamente para mantener sus privilegios, confirmando así lo que Valcárcel (2013) denuncia como «el espejismo de la igualdad».

\section{Discusión y conclusiones}

Siguiendo la reflexión de Cole (2015), los ataques y denigraciones mostrados en el apartado de resultados actúan como mecanismos de coacción para silenciar a la mujer feminista. A través de la sección de comentarios, los usuarios buscan en última instancia la sumisión de la mujer respecto al hombre, privándola de su participación en el ámbito público y confinándola en el entorno doméstico. El ejemplo más claro de ello lo reflejan todos aquellos comentarios que ordenan a la youtubera que "vuelva a la cocina». Como base conceptual se puede seguir el concepto de retórica disciplinaria formulado por Foucault (1975). Los usuarios ejercen una violencia sistemática sobre aquellas mujeres feministas que operan en la Red mediante el modelo disciplinario. Este último se inicia a través de la vigilancia virtual de sus actividades y movimientos en la plataforma web, en este caso YouTube. Este control puede verse reflejado en el gran volumen de comentarios que recibe el vídeo Why I'm... a feminist en un intervalo de tiempo muy reducido. En solo 20 días, entre las fechas 10 de abril y 30 de abril de 2016, se generan 850 comentarios. Todo ello nos proporciona un dato claro sobre su importante seguimiento, sobre todo si se tiene en cuenta que este vídeo fue publicado hace aproximadamente cuatro años, en abril de 2014. Posteriormente, la disciplina se materializa cuando se "castiga» su actuación mediante la ciberviolencia explícita. Durante la franja temporal analizada, el vídeo recibe un total de 478 comentarios explícitamente ciberviolentos dirigidos primordialmente a la youtubera, a las mujeres feministas y a las mujeres en general. Dentro de estos comenta- 
rios se identifican múltiples estrategias de ciberviolencia, desde los insultos, sarcasmos, imposiciones y deseos de dañar hasta las objetivaciones sexuales, criminalizaciones y difamaciones, llegando a las amenazas explícitas, generales y sexuales. En este sentido, se puede observar que el marco de ciberviolencia resulta mucho más complejo y va más allá de la objetivación sexual que resalta Cole (2015). Así mismo, estas estrategias no operan independientemente las unas de las otras, sino todo lo contrario: muchos usuarios aplican estrategias de ciberviolencia múltiples para magnificar su agresión hacia todo aquello relacionado con la mujer y el feminismo. Las estrategias más comunes, el sarcasmo y el insulto, se combinan frecuentemente con el resto de mecanismos de coacción. Particularmente, y volviendo a la reflexión de Cole (2015), el uso del sarcasmo normaliza y naturaliza el discurso de la violencia. Los comentarios irónicos y los recursos lingüísticos, como los hashtags, los emoticonos o los memes, son utilizados para convertir la ciberviolencia contra la mujer y antifeminista en algo socialmente aceptable. Así mismo, la «incapacidad mental o locura innata» que se atribuye a las mujeres feministas es otro aspecto a tomar en consideración. Esta clase de ataques conforman una tendencia muy pronunciada entre los usuarios que se proponen minar la credibilidad y la autoestima feminista.

Paralelamente, a la vez que se intenta "disciplinar» a las mujeres feministas, también se denigra a otros colectivos por su orientación sexual, «raza», especie, religión, «capacidad», etcétera. Es importante enfatizar este último aspecto ya que la intersección entre diferentes variables de opresión (Davis, 1983; Hill Collins, 1990; Hooks, 1989) es una cuestión que resulta frecuentemente desatendida por parte de la literatura académica, especialmente en este campo de estudio (Daniels, 2009). La coacción ejercida en contra de aquellos colectivos que se desvían de las normas patriarcales dominantes busca su exclusión de la toma de decisiones y su reubicación en un lugar concreto de la sociedad.

Al margen de la ciberviolencia explícita, se ha podido comprobar que la muestra analizada también ha generado 212 comentarios no ciberviolentos que hay que tener en cuenta porque exponen argumentos que derivan de una incomprensión profunda del feminismo. Generalmente, los usuarios/as manifiestan oponerse al feminismo porque consideran que este defiende la supremacía de la mujer. De este modo, ya sea por desinformación o por voluntad propia, los autores de los comentarios exponen una definición contraria a los fundamentos del feminismo: la igualdad social, política y económica por razón género. Así mismo, la dinámica de "victimización masculina» presente en estos comentarios es otro ejemplo de la incomprensión de las preocupaciones y problemáticas reales que aborda el feminismo. La pregunta continua "¿Y qué pasa con los hombres?» ignora la situación de privilegio que todavía mantienen los hombres respecto a las mujeres en todos los niveles y sectores (cultural, institucional, social, político, económico, etcétera). Además, no tienen en cuenta que el feminismo también se opone a todas aquellas opresiones que el sistema patriarcal puede ejercer en los mismos hombres (por ejemplo, a la hora expresarse emocionalmente, seguir determinados roles sociales, heteronormatividad, 
etcétera). A nivel general, la incomprensión del feminismo no posibilita ningún tipo de conversación productiva, más bien promueve indirectamente situaciones de ciberviolencia a través de la perpetuación de prejuicios y estereotipos relacionados con la mujer y el feminismo. Como indica el informe realizado por el Parlamento Europeo (2016), estas visiones sesgadas conforman la base para alimentar situaciones futuras de violencia en contra de la mujer. Por ello, se ha considerado que estos comentarios mantienen inevitablemente una postura de "complicidad» con la ciberviolencia.

El presente estudio intenta romper la omisión académica que se ha generado alrededor de la ciberviolencia contra la mujer y el feminismo (Burke, et al., 2015). Pero, en última instancia, a través de la exposición de los estudios desarrollados en este campo y de los resultados obtenidos, se pretende demostrar la relevancia de esta problemática y la necesidad de actuar ante su creciente normalización.

Los roles y actitudes ciberviolentas que se han podido originar en la sección de comentarios de YouTube son un reflejo la desigualdad y violencia de género que persiste en las sociedades actuales. Por ello, de acuerdo con las Naciones Unidas (2015), la concienciación y la sensibilización social es el primer paso para cambiar las normas y actitudes que naturalizan este tipo de violencia perpetrada en contra de la mujer (Burke et al., 2015). A modo de ejemplo, es necesario crear campañas en las redes sociales que reflejen las experiencias que viven las mujeres en el mundo online, para mostrar la conexión tan estrecha que surge entre los comportamientos ciberviolentos, el poder, y el género (West, 2014). Así mismo, «las plataformas de Internet y de las redes sociales deben adoptar medidas para ayudar de manera proactiva a las víctimas de acoso a denunciar abusos» (FRA, 2014: 13). En palabras de Fascendini \& Fialova (2014): «Online platforms should create clear options for getting images or abusive content removed, they should respond immediately and effectively to complaints from victims of online abuse, and finally, they should establish genuine consent for terms of use» (citado en West 2014: 26). Además, y según las Naciones Unidas (2015), un seguimiento riguroso y una implementación efectiva de las reglas que prohíban la ciberviolencia contra la mujer van a ser condiciones sine qua non para que Internet se convierta en un espacio respetuoso y que brinde oportunidades de empoderamiento para las mujeres y las chicas, y por extensión, para los hombres y los chicos. No obstante, esta intervención debe asegurar en todo momento sus límites, de manera que no pase a ser un simple acto de "vigilancia» y diferencie entre los derechos públicos y privados que los sujetos ostentan en la Red y en la vida «real» (Ess, 2014).

Ante la ausencia de respuesta política, muchos grupos ciberfeministas han tomado el mando y han creado iniciativas dirigidas a luchar en contra de la ciberviolencia. A modo de ejemplo, Take Back the Tech (Mapping technology related violence against women) funciona como una plataforma de empoderamiento para todas aquellas mujeres de cualquier rincón del mundo afectadas por la violencia de género online, y les ofrece un espacio para que alcen su voces 
y compartan sus experiencias, testimonios y estrategias de supervivencia. Con ello, pretenden hacer visible aquello «invisible» para la sociedad:

It is about demanding the world see what it doesn't want to see...we are calling connections between women who think their stories are isolated, insignificant or anomalous, to seeing a global picture of the violence that women all over the world are facing, simply because we are women, and that each story matters (Take Back theTech, 2016).

De forma similar, IHeartMob es una iniciativa dedicada a proveer apoyo emocional a todas aquellas personas que sufren algún tipo de agresión o acoso en el ciberespacio. La comunidad online está pensada para fortalecer las relaciones empáticas y solidarias entre las personas, de forma que entre todos/as se inicie un camino para acabar con la violencia virtual. Por otro lado, cada vez más mujeres utilizan las mismas redes sociales para adoptar actuaciones diarias dirigidas a desafiar la ciberviolencia sexista. Por ejemplo, en muchas ocasiones las mujeres denuncian esta violencia mediante la publicación de los comentarios ofensivos que reciben a través de hashtags como \#youtubemisoginy, \#mencallmethings o \# YesAllWomen. Particularmente, las blogueras y youtuberas feministas tienden a publicar en sus propios blogs o canales algunas de las agresiones diarias que han de soportar. En determinadas ocasiones, estas últimas crean vídeos donde directamente responden a algunos de los comentarios ofensivos o dan consejos y recomendaciones sobre cómo combatir el ciberbullying. En este sentido, los vídeos Feminist responds to online misoginy (Watanabe, 2015b), How do I deal with online harassment (Blaque, 2015) o What it's like to be a woman on YouTube (Buzzfeed, 2015) representan buenos ejemplos. De forma destacable, la youtubera Anita Sarkeesian ha ejercido múltiples acciones para denunciar la campaña misógina que ha vivido tras la creación de su proyecto centrado en la deconstrucción de los videojuegos desde un punto de vista de género. Paradójicamente, la indignación frente a los ataques que recibió esta youtubera acabó provocando que cerca de 7.0000 personas contribuyeran a su campaña y recaudará 25 veces más fondos para su proyecto (TEDx Talk, 2012). En este sentido, es importante no olvidar que muchas mujeres y hombres empatizan con las vivencias y reflexiones personales que estas mujeres comparten en YouTube. Posiblemente, es esta capacidad de influencia y transformación social la razón por la cual se les ataca sistemáticamente.

Todos estos ejemplos de activismo y contestación demuestran que la ciberviolencia centrada en silenciar a la mujer feminista en muchas ocasiones se traduce en un intento fallido. A pesar de los numerosos obstáculos que se interponen en su camino y de la violencia sufrida, muchas blogueras y youtuberas, como Laci Green, continúan trabajando intensamente por la igualdad de género y la justicia social. Y, a la hora de hacerlo, ellas aprovechan la otra faceta que puede proveer Internet, aquella que ofrece oportunidades de empoderamiento, inclusión, esperanza y empatía. Las posibilidades ligadas al mundo virtual pueden ser inmensas, pero siempre dependerán del uso que se haga de ellas. 


\section{Referencias bibliográficas}

Abraham, Linda; Mörn, Marie P. y Vollman, Andrea (2010). "Women on the web: How women are shaping the Internet». comScore Whitepaper, Inc. <https:// www.comscore.com/Insights/Presentations-and-Whitepapers/2010/Womenon-the-Web-How-Women-are-Shaping-the-Internet> [Consulta: 10 abril de 2016].

Agencia de los Derechos Fundamentales de la Unión Europea (2014). Violencia de género contra las mujeres: una encuesta a escala de la UE: Resumen de Conclusiones. Luxemburgo: Oficina de Publicaciones de la Unión Europea. <http://fra. europa.eu/sites/default/files/fra-2014-vaw-survey-at-a-glance_es_0.pdf >.

Barlett, Jamie; Norrie, Richard; PATel, Sofia; Rumpel, Rebekka y Wibberley, Simon (2014). Misoginy on Twitter. Londres: DEMOS. <https://www.demos. co.uk/files/MISOGYNY_ON_TWITTER.pdf >.

BARTOW, Ann (2009). "Internet Defamation as a Profit Center: The Monetization of Online Harassment». University of New Hampshire. School of Law, 32, 384-429.

BELA-LobedDe, Desirée (2013). Ser mujer negra en España. <https://www.youtube. $\mathrm{com} /$ watch?v=Fevqny1XMbo $>$ [Consulta: 20 de abril de 2016].

Blaque, Kat (2014). \#MenimistTwitter + Antifeminism. <https://www.youtube.com/ watch? $v=$ fnKYx4QFbpQ $>$ [Consulta: 20 de abril de 2016].

- (2015). How do I deal with online harassment? <https://www.youtube.com/ watch?v=0Iw5i6HN_ZE $>$ [Consulta: 15 abril 2016].

- (2016). Don't read the Comments. <https://www.youtube.com/watch?v=28muwCKT1uQ> [Consulta: 20 abril 2016].

Burke Winkelman, Sloane; Oomen Early, Jody; D. Walker, Ashley; Chu, Lawrence y YICK-FLANAGAN, Alice (2015). «Exploring cyber harassment among women who use social media». Universal Journal of Public Health, 3 (5), 194-201. <https://doi.org/10.13189/ujph.2015.030504>.

BUZZFEED (2015). Here's what it's like to be a woman on YouTube, <http://everydayfeminism.com/2015/02/woman-on-youtube/> [Consulta: 25 abril 2016].

CHo, Ji Y. y LeE, Eun-Hee (2014). «Reducing confusion about grounded theory and qualitative content analysis: Similarities and differences». The Qualitative Report, 19 (64), 1-20. < http://nsuworks.nova.edu/tqr/vol19/iss32/2/>.

Citron, Danielle Keats (2009). «Law's expressive value in combating cyber gender harassment». Michigan Law Review, 3 (108), 373-415. <http://digitalcommons. law.umaryland.edu/cgi/viewcontent.cgi? article $=1687 \&$ context=fac_pubs $>$.

Cole, Kirsti K. (2015). «It's like she's eager to be verbally abused: Twitter, trolls, and (en)gendering disciplinary rethoric». Feminist Media Studies, 15 (2), 356-358. <https://doi.org/10.1080/14680777.2015.1008750>.

DANIELS, Jessie (2009). «Rethinking cyber feminism(s): Race, gender, and embodiment». Women's Studies Quarterly, 37 (1 y 2), 101-124. $<$ https://doi.org/10.1353/wsq.0.0158>.

Davis, Angela (1983). Women, Race and Class. New York: Vintage.

De Miguel, A. y Boix, M. (2003) «Los géneros de la red: los ciberfeminismos». Mujeres en Red, <http://www.mujeresenred.net/IMG/pdf/ciberfeminismo-demiguelboix.pdf> (Accedido 20 de abril 2016).

Ess, Charles (2014). Digital media ethics (2a ed.). Digital Media and Society Series. Cambridge: Polity Press. 
Faludi, Susan (1991). Backlash: The Undeclared War against American Women. Philadelphia: Temple University Press.

FerreirA, Carolina B. C. (2015) «Feminism on the Web: Lines and forms of action in contemporary feminist debate». Cadernos Pagu, (44), 199-228. $<$ https://doi.org/10.1590/1809-4449201500440199>.

Fielding, Nigel G., Lee, Raymond M. y Blank, Grant (2008). On Line Research Methods. Londres: Sage.

FILIPOVIC, Jill (2007). «Blogging while female: How Internet misogyny parallels 'real world' harassment». Yale Journal of Law \& Feminism, 19 (10), 295-303. <http:// digitalcommons.law.yale.edu/cgi/viewcontent.cgi?article $=1268 \&$ context $=y j l f>$.

FouCAUlT, Michel (1975). Vigilar y castigar. Madrid: Siglo XXI de España Editores, SA.

GoldberG, Michelle (20 de febrero de 2015). «Feminist writers are so besieged by online abuse that some have begun to retire». The Washington Post. <https://www. washingtonpost.com/opinions/online-feminists-increasingly-ask-are-the-psychiccosts-too-much-to-bear/2015/02/19/3dc4ca6c-b7dd-11e4-a200-c008a01a6692 story.html> [Consulta: 20 abril 2016].

Green, Laci (2014). Why I'm... a feminist. <https://www.youtube.com/ watch?v=UwJRFClybmk> [Consulta: 20 de abril de 2016].

Gurumurthy, Anita y Menon, Niveditha (2009). "Violence against women via cyberspace». Economic and Political Weekly, 44 (40), 19-21.

GuTIÉRREZ DEL MORAL, Leonardo (2014). Curso de ciberseguridad y hacking ético 2013. Sevilla: Punto Rojo Libros.

Haraway, Donna (1991). Manifiesto Cyborg: Ciencia, tecnología y feminismo socialista a finales del siglo XX. <http://www.icesi.edu.co/blogs/antro_conocimiento/ files/2012/02/Haraway_MANIFIESTO-CYBORG.pdf > [Consulta: 20 de abril de 2016].

Hess, Amanda (2015). «Women aren't welcome here». The Best American Magazine Writing 2015. Columbia University Press. $<$ https://doi.org/10.7312/asme16959-004>.

Hill Collins, Patricia (1990). Black feminist thought. Knowledge, consciousness and the politics of empowerment. Nueva York: Routledge.

HoOKs, Bell (1989). Talking back: Thinking feminist, thinking black. Boston: South End.

Hsien, Hsiu-Fang y SHAnnon, Sarah E. (2005). "Three approaches to qualitative content analysis». Qualitative Health Research, 15 (9), 1277-1288. <https://doi.org/10.1177/1049732305276687>.

IHeartMob (2016). About IHeartMob. <https://iheartmob.org/pages/about> [Consulta: 20 de abril de 2016].

Joiner, R., Gagin, J., Brosnan, M., Cromby, J., Gregory, H., Guiller, J., Maras, P. and Moon, A. (2012), «Gender, Internet Experience, Internet Identification and Internet Anxiety: a Ten Year Follow-Up». Cyberpsychology, Behavior, and Social Networking, 15 (7). pp. 370-372.

Laci Green Youtube SeX Ed for the InTernet (2018). About Laci Green Youtube sex ed for the Internet. <http://www.lacigreen.tv/about> [Consulta: 15 de enero de 2018].

LAZO, K. (2013). Feminism isn't dead, it's gone viral!, TEDxWomen, 2012, YouTube, TEDx Talks. <https://www.youtube.com/watch?v=NNpUxKSmeE4> [Consulta: 20 de abril de 2016]. 
Marlin-Bennett, Renée y Thornton, E. Nicole (2012). «Governance within social media websites: Ruling new frontiers». Telecommunications Policy, 36, 493-501. <https://doi.org/10.1016/j.telpol.2012.01.002>.

MARUSIC, Kristina (23 de febrer de 2015). «Sorry trolls, you're not going to win the battle against social justice warriors». MTV News. <http://www.mtv.com/ news/2087859/trolls-sjw-laci-green/> [Consulta: 20 de abril de 2016].

MathiEU, Stephanie E. (2011). Misogyny on the web: Comparing negative reader comments made to men and women who publish political commentary online. Degree Masters of Arts, University of Missouri-Columbia. <https://mospace.umsystem. edu/xmlui/bitstream/handle/10355/11494/research.pdf?sequence=3 > .

MaYrING, Philipp (2000). «Qualitative Content Analysis». Forum: Qualitative Social Research, 1 (2). <https://doi.org/10.1007/978-94-017-9181-6_13>.

MCDonald, Soraya Nadia (2014). "Gamergate': Feminist video game critic Anita Sarkeesian cancels Utah lecture after threat». The Washington Post. <https://www. washingtonpost.com/news/morning-mix/wp/2014/10/15/gamergate-feminist-video-game-critic-anita-sarkeesian-cancels-utah-lecture-after-threat-citing-police-inability-to-prevent-concealed-weapons-at-event/> [Consulta: 20 de abril de 2016].

Moya, Miguel y ExPÓsiTo, Francisca (2001). «Nuevas formas, viejos intereses: neosexismo en varones españoles». Psicothema, 13.

Osborne, Raquel (2009) Apuntes sobre violencia de género. Barcelona: Edicions Bellaterra.

Parlamento Europeo (2016). The issue of violence against women in the European Union. Directorate-General for Internal Policies, Policy Department: Citizen's Rights and Constitutional Affairs. Bruselas: Bonewit, A. \& De Santis, E. <http://www.europarl.europa.eu/RegData/etudes/STUD/2016/556931/IPOL_ STU(2016)556931_EN.pdf>.

Pedraza, William J.; Betancur, Claudia A. y Velandia, Benjamín V. (2011). «La ciberviolencia: Nuevas formas de concebir la violencia en el ciberespacio». Revista INPAHU, 7, 69-80. <https://issuu.com/la39/docs/revista_inpahu_no_7_version_digita>.

Perdomo Reyes, Inmaculada (2016). «Género y tecnologías. Ciberfeminismos y Construcción de la Tecnocultura Actual». Revista Iberoamericana, 11 (31), 1-19.

Plant, Sadie (1997). Zeroes and ones: Digital women and the new technoculture. Nueva York: Doubleday.

RAMSEY, Franchesca (2012). How slut shaming becomes victim blaming. <https://www. youtube.com/watch?v=113h8fzv-BM> [Consulta: 20 de abril de 2016].

SAHIN, Mustafa (2012). "The relationship between the cyberbullying/cybervictmization and loneliness among adolescents». Children and Youth Services Review, 34, 834-837.

<https://doi.org/10.1016/j.childyouth.2012.01.010>.

Salmons, Janet (2016). Doing Qualitative Research Online. Londres: Sage.

SÁnCHEZ, María (6 de marzo de 2016). "Qué asco das negra de mierda”: el mensaje racista que según YouTube no vulnera sus propias normas». El Pais. <http://verne. elpais.com/verne/2016/03/06/articulo/1457283952_116941.html> [Consulta: 20 de abril de 2016].

SARKeESIAN, Anita (4 de diciembre de 2012). TEDxWomen 2012, TEDx Talks. <http://www.youtube.com/watch?v=GZAxwsg9J9Q> [Consulta: 20 de abril de 2016]. 
- (2016). Feminist Freqüency Reviews. <https://www.youtube.com/playlist?list=PLn4ob_5_ttEZcooN5ySdrYXxQnYp0uh1U> [Consulta: 20 de abril de 2016].

STATISTA (2016a). Average monthly social media user engagement as of June 2015, by region and gender (in hours). <http://www.statista.com/statistics/214698/averagehours-per-visitor-on-social-networking-by-region/> [Consulta: 10 de abril de 2016].

- (2016b). Gender distribution of active social media users worldwide as of $1^{\text {st }}$ quarter 2013, by platform. <http://www.statista.com/statistics/274828/gender-distributionof-active-social-media-users-worldwide-by-platform/> [Consulta: 10 de abril de 2016].

TAKe BaCK The TeCH (2016). About Take Back The Tech. <https://www.takebackthetech.net/mapit/page/index/2> [Consulta: 25 de abril de 2016].

TAUB, A. (2014). "The sexual threats against Emma Watson are an attack on every woman", VOX Violence against Women. <http://www.vox. $\mathrm{com} / 2014 / 9 / 23 / 6832243 /$ the-sexual-threats-against-emma-watson-are-an-attackon-women> [Consulta: 20 de abril 2016].

Time (16 de marzo de 2016). The 30 most influential people on the Internet. <http:// time.com/4258291/30-most-influential-people-on-the-internet-2016/> [Consulta: 15 de abril de 2016].

TRUE, Jacqui (2012). From domestic violence to war crimes. The political economy of violence against women. University Press Scholarship Online: Oxford Scholarship Online. <https://doi.org/10.1093/acprof:oso/9780199755929.003.0001>.

United Nations Broadband COMMISSION For Digital DEVElopMENT Working GROUP ON BROADBAND AND GENDER (2015). Cyber violence against women and girls: A world - wide wake up call. United Nations Entity for Gender Equality and the Empowerment of Women (UN Women), United Nations Development Programme (UNDP).

VALCÁrCEL, Amelia (2013). Feminismo en el mundo global. Valencia: Cátedra.

WajCMAn, Judy (2006). El tecnofeminismo. Madrid: Cátedra.

WATANABE, Marina (2014). But what about the men? [En línea]. <https://www.youtube.com/watch?v=gQ_vUkkWfsA $>$ [Consulta: 25 de abril de 2016].

- (2015a). Why I delete comments. [En línea]. <https://www.youtube.com/ watch?v=360jOMd_h30\&list=PLfyCXMlxeWkgPOs4ZubIbxf_6HYv0ZQ9F\& index $=18>$ [Consulta: 20 de abril de 2016].

- (2015b). A feminist responds to online misoginy. [En línea]. <https://www.youtube. com/watch?v=CbbbF5pACsk> [Consulta: 25 de abril de 2016].

WEST, Jessica (2014). Cyber-Violence against women. Vancouver: Battered Women's Support Services. [En línea]. <http://www.bwss.org/wp-content/uploads/2014/05/ CyberVAWReportJessicaWest.pdf>.

ZOONEN, Liesbet van (2002). "Gendering the Internet: Claims, controversies and cultures». European Journal of Communication, 17 (1), 5-23. 
